\title{
A Service Supply Chain Framework from Process Perspective
}

\author{
Ma Xuesong \\ School of Management, Huazhong University of Science and Technology, Wuhan, China \\ ma_xs@163.com
}

\begin{abstract}
The nature of services is a process of value creating process, starting from customer demand, operating through service supplier cooperating with customer, ending by customer service evaluation and paying service expense. Base on this point, a service supply chain framework is created. The analysis result indicates that, it is critical for service supply chain to provide customer the resource effectively and efficiently and then create the valve to meet customer's demands by resource transforming, which is the purpose and key point of the service supply chain setting up and operating. This attribute makes service supply chain a flat structure chain rather than multiple levels of layer and node as manufacturing supply chain.
\end{abstract}

Keywords: Service; Service supply chain; Service system framework.

\section{Introduction and Literature Review}

In 2004, American scholar Ellram, LM et al. first proposed the concept of service supply chain and then opened the curtain of service supply chain research ${ }^{[1]}$.Currently there are many different understandings of service supply chain. Generally they can be summarized as three points of view as follows:

(1) Define the service supply chain from after-sales service perspective, called server supply chain management. It emphasizes the important role of the after-sales service in the enterprise to maintain the competitive advantage and obtain the profit. Server supply chain management can be defined as a management model to ensure the product after-sales service running smooth by integrating all support activities such as service plan, service operation, repair and maintenance, spare parts management etc. ${ }^{[2,3]}$

(2) Another understanding of service supply chain is based on the perspective of service outsourcing, which was first proposed by Ellram, LM et al. It regards service supply chain management as a management model by integrating information flow, service flow, capital flow, service process, service performance etc. during the outsourcing process from initial service suppliers to final customer in the service outsourcing enterprises. ${ }^{[1]}$

(3) The definition of the third service supply chain is the traditional supply chain management system which is formed by the application of the supply chain management idea in the manufacturing industry. This view emphasizes the difference between service industry and manufacturing industry. Jin Liyin pointed out service supply chain management is a new management model by delivering service rather than product or logistics to customers with the development of the internet and the emergence of global manufacturing in recent years. ${ }^{[4]}$

Compared with foreign research, domestic research is more concerned with the concept and connotation of service supply chain. Different scholars have given the concept of service supply chain in the specific industries, such as tourism, logistics, port, property, financial and securities and rental service supply chain. ${ }^{[5 \sim 10]}$

In brief, so far there is no unified and clear definition of service supply chain being provided in academia. Therefore, it is meaningful and important to analyze the nature of the service supply chain, so as to construct the service supply chain structure model to guide the operation of actual service supply chain. 


\section{Service Supply Chain Framework from Process Perspective}

It was well known that service is becoming a new dominant logic operation of the market, which is a value creation process by using particular resource or capacity (knowledge and skills) for entities. The core of service is a value creation process ${ }^{[11]}$. Based on this process point of view of service mentioned above, the service system model is built as follows.

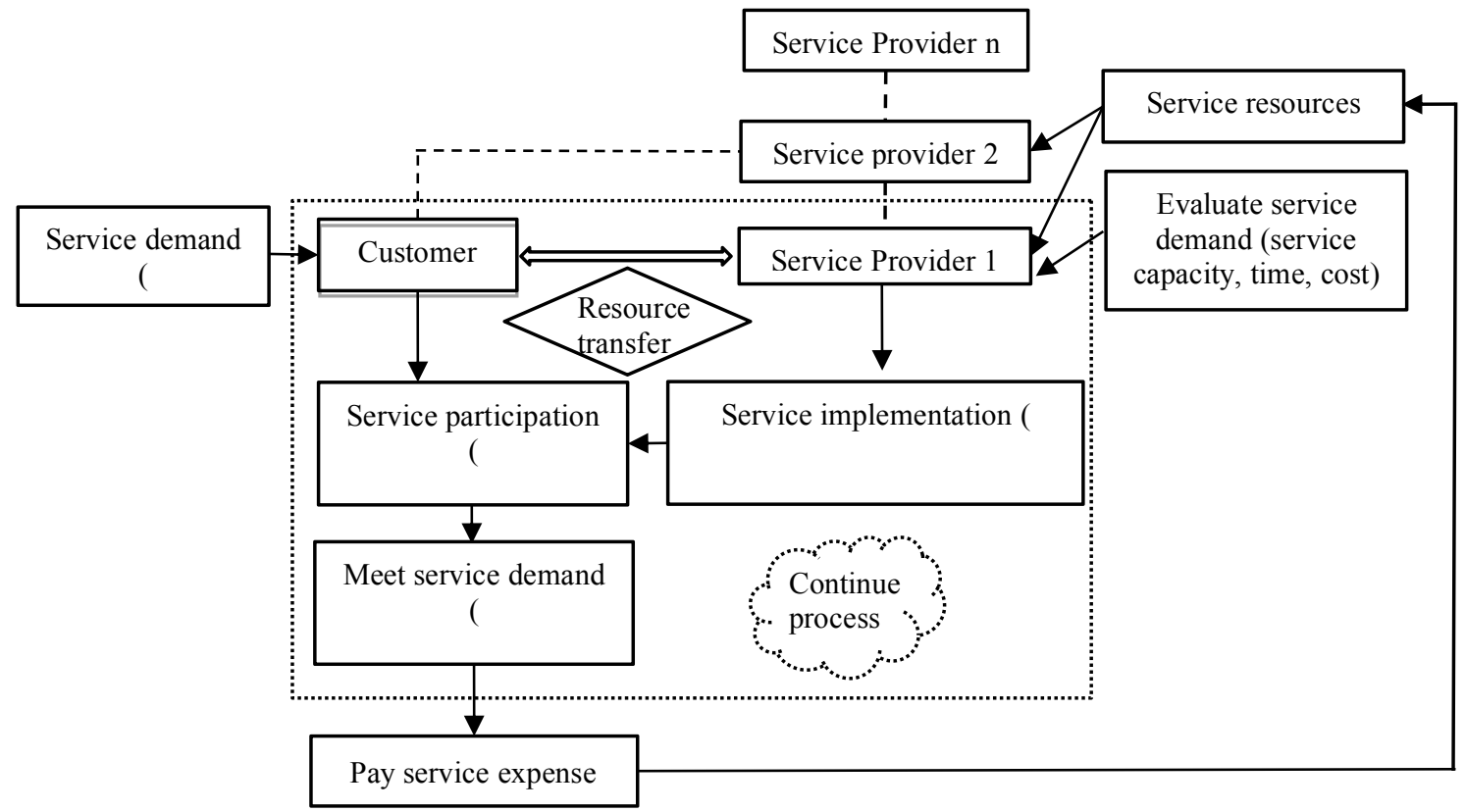

Figure 1. Service Supply Chain Model from Process Perspective

In this model, service demand is divided into two categories, that is, main demand and ancillary demand, denoted as, respectively. During service process, is prior to and should be met first. After receiving service demand generated by customers, service providers will evaluate and judge whether the service demand can be met according to their knowledge, skill, resource etc. The evaluation scope including service capacity/capability, service cost and service time. If the evaluation result is positive, service providers will draw agreement and sign contract to identify the service content, price etc. If the evaluation result is negative, service providers will outsource to find joint partners to provide the service. If the service cannot be outsourced, the process will has to stop and cannot continue.

After that, the service providers will provide service to customers, that is, the value provided, denotes as, which including the value of the tangible and intangible resources value when the service implementation consumed. This value is the service providers' unilaterally value, regardless of the customers. During the service process, customers will perceive the value they get, denotes as ., is index of perceive value, normally means the service provided is attenuated. If, means customers think the service value perceived is beyond the expectation. If , means customers think the service is harmed and no any value added. Here is generated from service joint efforts and cooperation. Without customers' participation, service providers cannot provide the service and only can provide service suggestions ${ }^{[11]}$. Here the service process is a resource transfer process, under the resource input from both customers and service providers, the service supply chain can be established. Since customers participate the service directly, the service supply chain will be a flat structure rather than traditional product supply chain with clear hierarchy and a large number of link nodes.

After the service finished, customer will evaluate the whole service process and compare the with and. The values of, are represented as, respectively. If, customer think the service meet the demand and satisfied with it. If , customer will not be satisfied with the service, the service does not meet the customer demand. Finally, customer will pay for the service base on the contract signed before service process started, normally the amount is the same as service price. In actual cases, customers may not know the real values of their demands and lead to the deviation of self-evaluation, 
that is, sometimes and, which gives the service supply chain management chance to improve the customers' perceived values.

Assume $V_{f}$ and $V_{c}$ are concave function. Before service begins, both service providers' input value and customers' perceived value are zero. With the implementation of the service, the input value of service providers $V_{f}$ increases to reach required value $V_{f 1}$ to meet customers' main demand, then continue to increase until the value $V_{f 2}$ to meet customer ancillary demand $V s$, If service providers continue to increase the input value to $V_{f 3}$, and then customers will feel premium service beyond their demands. If service providers just input $V_{f 2}$, to reach, and continue to input $V_{f 3}$, to get same customers satisfaction, at this time $V_{f}$ and $V_{c}$ are convex function. We can find, that means service providers can input less value/resource to meet or beyond the customers demand. This can be achieved by servicer demand management and servicer marketing management etc. and belongs to another topic, so no more discussion here.

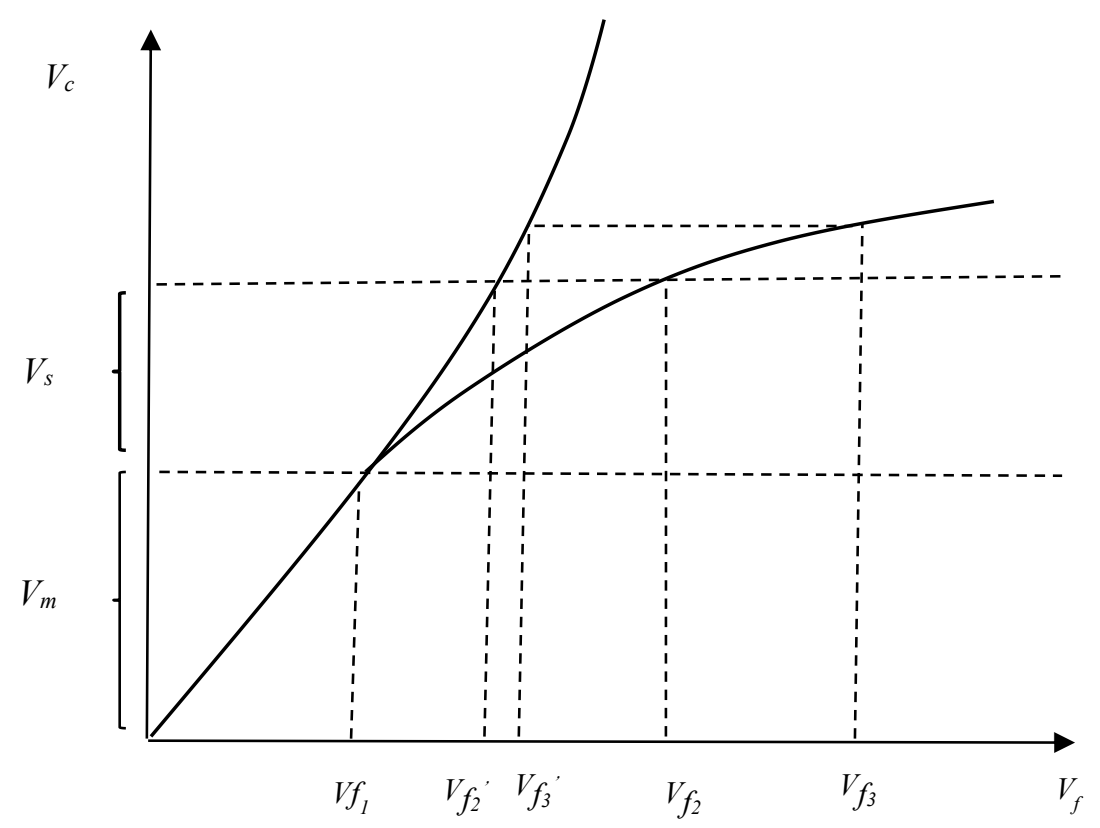

Figure 2. Customers' perceived value vs. service providers' input value graph

\section{Case study}

This service supply chain framework model has universal applicability. For example, it can be used to explain and describe the logistics services supply chain clearly.

Assume company A needs ship a batch of goods from China to United States within 10 working days. A searched and selected logistics company B as service provider to finish this job. After receiving this service request, B evaluated and known that they have a warehouse to store goods, vehicles to transport goods, personnel and US Route transport experience, hence thought they have the capacity/capability to achieve the demand. Hence B quoted and signed a contract of carriage with A. However, the delivery of goods from China to the United States needs declaration, which is beyond its ability to service. So B prepared the declaration documentation and submitted to customs $\mathrm{C}$ for approval. After completing clearance procedures by $\mathrm{C}$ followed relevant policies and regulations, the goods delivered smoothly and arrived US one day ahead of the schedule. A verified and paid the service fees in accordance with the provisions of the contract to $\mathrm{B}$, the service process is completed successfully.

In this case, A acted as a customer, service needs is the delivery of goods to the designated location in US, which include the main demands of time (10 days delivery schedule), goods arriving at the designated destination, cargo security etc. Ancillary demands include professional services, 
response in time, service attitude etc. B acted as a service provider. Service resources include not only warehouses, vehicles, personnel and other tangible resources, but also a professional logistics technology, knowledge of customs procedures and other intangible resources. B only could complete the whole service process after getting the customs service provided by $\mathrm{C}$, so $\mathrm{C}$ became a secondary service provider of $\mathrm{B}$ to provide cargo transport services together with $\mathrm{A}$. Thus, a tripartite service supply chain was built up by A, B, C.

In the process of delivery of goods and services, A cooperated with B mutually, A provided B the goods, cargo information (including product name, quantity, dangerous level, waybill number, shipping destination address, the consignee name, contact information, etc.); B provided A the delivery services (including checking cargo inventory, packaging, air and land transport routes determining, booking cargo space, preparing containers, customs data preparation, shipping, cargo tracking, etc.); Customs C provided A and B the customs clearance services (including customs document review approval, to charge the fees, etc.) and input the resources for the freight and create service values together. A felt the service value $\left(V_{c}\right)$ gradually increased until the final service demands $\left(D_{m}+D_{s}\right)$ were met during tracking the logistics process and understanding the real time situation. And B also continued to invest human, material and other resources in the shipping process so that value $\left(V_{f}\right)$ was on rising until it reached the value of demand () to make the delivery of goods reached US one day in advance. So A was satisfied and paid for services. B could made this service income as profit or continue to invest the resources input. Till now the service process was ended.

In this continuing process, a service supply chain from process perspective was created by issuing $A^{\prime}$ s service demand as a starting point, A, B, C jointly created value for freight service process via exchanging resources, the service demands were met as a ending point. Same as this, other service supply chains such as finance service supply chain, medical service supply chain etc. also can be described by this framework model. Given the logic is same, no more discussion here.

\section{Conclusions}

Services are "the application of specialized competences (knowledge and skills) through deeds, processes, and performances for the benefit of another entity or the entity itself”. This paper maintains that the nature of services is a process of value creating process, starting from customer demand, operating through service supplier cooperating with customer, ending by customer service evaluation and paying service expense. Base on this point, a service supply chain framework is created. The analysis result indicates that, it is critical for service supply chain to provide customer the resource effectively and efficiently and then create the valve to meet customer's demands by resource transforming, which is the purpose and key point of the service supply chain setting up and operating. This attribute makes service supply chain a flat structure chain rather than multiple levels of layer and node as manufacturing supply chain.

This model is constructed by mostly qualitative analysis. Next, quantitative analysis will continue to be developed into the service supply chains model to show the relationships between each parameters.

\section{References}

[1] Ellram L M, Tate W L, Billington C. Understanding and Managing the Services Supply Chain [J]. Journal of Supply Chain Management, 2004, 40(4):17-32.

[2] Dirk de Waart, Kemper S. 5 Steps to Service Supply Chain Excellence [J]. 2004, 8(1):28-35

[3] Saccani N, Johansson P, Perona M. Configuring the after-sales service supply chain: A multiple case study[J]. International Journal of Production Economics, 2007, 110(s 1 - 2):52-69.

[4] Jin India. Service supply chain management, customer satisfaction and business performance of [J]. Chinese management science, 2006, 14 (2): 100-106. 
[5] Zhang Yingzi. Preliminary study on tourism service supply chain management [J]. Journal of Yanbei Normal College, 2005, 21 (1): 22-24.

[6] Ren Jie. Research on integrated logistics service provider selection based on logistics service supply chain mode [J]. Shopping mall modernization, 2006 (9S): 111-112.

[7] Yang Mingming. Hongkong port service supply chain [J]. China logistics and purchasing, 2006 (10): 56-58.

[8] Li Congdong, Chen Xiaofeng. Study on the integration of multi service and supply chain management in residential areas [J]. Industrial engineering, 2004 (4): 41-45.

[9] Fu Qiufang, Lin Wei. Research on the structure of China's financial security service supply chain [J]. International economic and trade exploration, 2008 (11): 45-49.

[10] Mao Chaoyan, Liang Xi. The supply chain of circular economy and the implementation strategy of the leasing service supply chain [J]. Modernization, 2008 (34): 36-37.

[11] Vargo S L, Lusch R F. Evolving to a new dominant logic for marketing [J]. Journal of marketing, 2004, 68(1): 1-17. 